Directed self-assembly of nanogold using a chemically modified nanopatterned surface

This article has been downloaded from IOPscience. Please scroll down to see the full text article.

2012 Nanotechnology 23045602

(http://iopscience.iop.org/0957-4484/23/4/045602)

View the table of contents for this issue, or go to the journal homepage for more

Download details:

IP Address: 141.211.173.82

The article was downloaded on 26/06/2013 at $16: 14$

Please note that terms and conditions apply. 


\title{
Directed self-assembly of nanogold using a chemically modified nanopatterned surface
}

\author{
Robert Nidetz $^{1}$ and Jinsang Kim ${ }^{1,2,3,4}$ \\ ${ }^{1}$ Department of Materials Science and Engineering, University of Michigan, Ann Arbor, MI 48109, \\ USA \\ 2 Department of Chemical Engineering, University of Michigan, Ann Arbor, MI 48109, USA \\ ${ }^{3}$ Department of Biomedical Engineering, University of Michigan, Ann Arbor, MI 48109, USA \\ ${ }^{4}$ Macromolecular Science and Engineering Center, University of Michigan, Ann Arbor, MI 48109, USA
}

Received 11 October 2011, in final form 12 November 2011

Published 4 January 2012

Online at stacks.iop.org/Nano/23/045602

\begin{abstract}
Electron-beam lithography (EBL) was used to define an aminosilane nanopatterned surface in order to electrostatically self-assemble gold nanoparticles (Au NPs). The chemically modified nanopatterned surfaces were immersed into a Au NP solution to allow the Au NPs to self-assemble. Equilibrium self-assembly was achieved in only $20 \mathrm{~min}$. The number of $\mathrm{Au}$ NPs that self-assembled on an aminosilane dot was controlled by manipulating the diameters of both the Au NPs and the dots. Adding salt to the Au NP solution enabled the Au NPs to self-assemble in greater numbers on the same sized dot. However, the preparation of the Au NP solution containing salt was sensitive to spikes in the salt concentration. These spikes led to aggregation of the Au NPs and non-specific deposition of Au NPs on the substrate. The Au NP patterned surfaces were immersed in a sodium hydroxide solution in order to lift-off the patterned Au NPs, but no lift-off was observed without adequate physical agitation. The van der Waals forces are too strong to allow for lift-off despite the absence of electrostatic forces.
\end{abstract}

S Online supplementary data available from stacks.iop.org/Nano/23/045602/mmedia

(Some figures may appear in colour only in the online journal)

\section{Introduction}

There has been a great deal of interest in the precise patterning of colloids on surfaces [1-6]. Patterned colloids have been used for photonic crystals [7], sensors [8], and seeds for the growth of inorganic nanowires [9]. Electrostatic forces [10-20] are very popular for patterning colloids because they are quick and long-range. The main ways in which electrostatic forces have been used to pattern colloids are by using patterned polyelectrolytes $[11,15,21]$ or by using functional patterned surfaces [9-11, 17, 22, 23].

Gold nanoparticles (Au NPs) are among the most commonly patterned colloids due to their stability and the wide range of ligands available to passivate the nanoparticle surface. Electrostatic patterning of Au NPs usually involves citrate-capped Au NPs, which have a negative surface charge, and a positively charged template. An aminosilane, such as 3-aminopropyltrimethoxysilane (APTMS), is commonly used to direct the electrostatic self-assembly of negatively charged $\mathrm{Au}$ NPs on Si substrates. It is often used in conjunction with another functional molecule that repels or prevents the $\mathrm{Au}$ NPs from non-specifically depositing on the non-aminosilane patterned areas $[10,17,19,20,22]$. In other cases, the resist remains on the $\mathrm{Si}$ surface to enable easy removal of non-specifically bound Au NPs [9, 10].

Here, a top-down approach was used to pattern negatively charged $\mathrm{Au}$ NPs on a positively charged, nanopatterned surface that was fabricated by chemically modifying the electron-beam lithography (EBL) exposed surface of $\mathrm{SiO}_{2}$ coated $\mathrm{Si}$ wafers. An aminosilane was used to direct the self-assembly in the absence of resist or a functional molecule that repels or prevents the Au NPs from sticking to the 


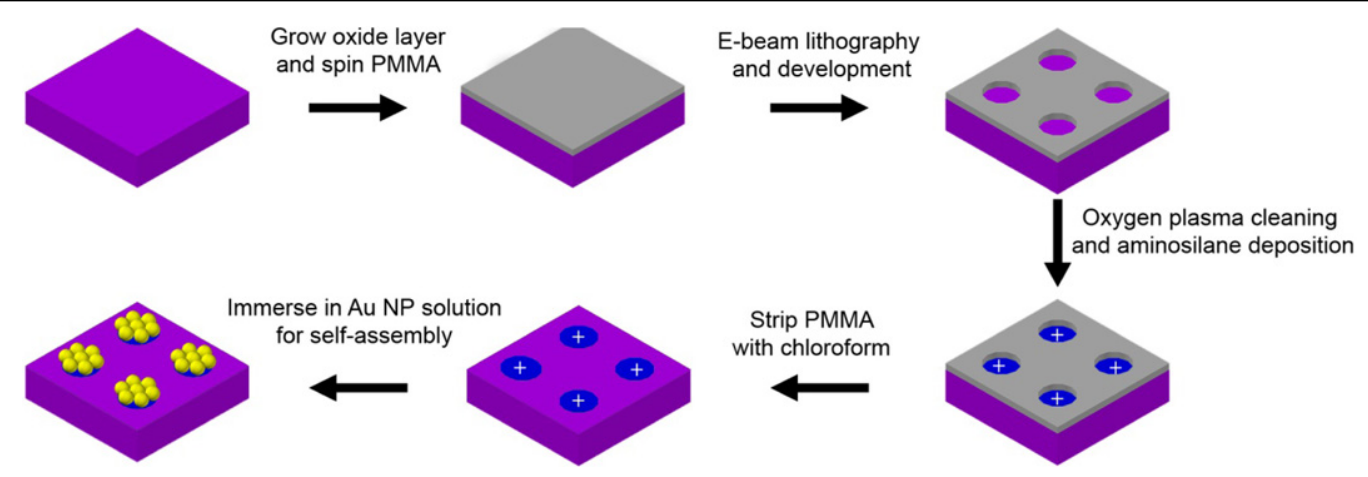

Figure 1. Scheme for creating the chemically modified nanopatterned surface and self-assembling the Au NPs. After an oxide layer is grown, PMMA is spin cast on a Si wafer. After e-beam lithography and development of the dot patterns, aminosilane is deposited in the patterned areas via gas-phase silanization. After removing the remaining PMMA resist, the sample is dipped into a solution of citrate-capped Au NPs to induce self-assembly.

substrate. The relationship between the pattern size and $\mathrm{Au}$ NP size was investigated as to how many particles would assemble on a pattern. Also, the immersion time of the chemically modified nanopatterned surface in the colloidal solution and the salt concentration of the colloidal solution were investigated to determine their effects on the colloidal self-assembly. The stability of the electrostatic patterning was also investigated by attempting to disassemble the Au NPs using sodium hydroxide $(\mathrm{NaOH})$ solutions.

\section{Experimental details}

\subsection{Electron-beam lithography}

$\mathrm{Si}$ wafers were purchased and a $45 \mathrm{~nm}$ layer of thermal oxide was grown. The oxide thickness was checked using ellipsometry. As schematically illustrated in figure 1, after a dehydration bake at $150^{\circ} \mathrm{C}$ for $5 \mathrm{~min}$ on a hot plate, PMMA resist (PMMA 950k A2, MicroChem) was spin cast onto the wafer at $4000 \mathrm{rpm}$ for $60 \mathrm{~s}$ to obtain a resist thickness of $\sim 65 \mathrm{~nm}$. A pre-bake was then performed by heating the wafer at $170{ }^{\circ} \mathrm{C}$ in an oven for $30 \mathrm{~min}$.

Electron-beam lithography (EBL) was performed at $20 \mathrm{keV}$ with a $10 \mu \mathrm{m}$ aperture using a Raith 150 (Raith). $10 \mu \mathrm{m}$ by $10 \mu \mathrm{m}$ arrays of dots were fabricated with a $500 \mathrm{~nm}$ pitch for multiple exposure doses $(10,20,30, \ldots, 100 \mathrm{fC})$ per sample with a large crosshair for easy visibility. After exposure, the samples were developed by immersing them in a $1: 3(\mathrm{v} / \mathrm{v})$ mixture of MIBK and IPA for $20 \mathrm{~s}$, immersing them in IPA for $30 \mathrm{~s}$, and drying them under a stream of $\mathrm{N}_{2} \cdot \mathrm{O}_{2}$ plasma reactive ion etching $\left(250 \mathrm{mT}, 17 \% \mathrm{O}_{2}, 180 \mathrm{~W}, 15 \mathrm{~s}\right)$ was used to remove any trace organics from the wafer surface after development.

\subsection{Silanization}

3-aminopropyltrimethoxy silane (APTMS, 97\%, Sigma) and 3-aminopropyldimethylethoxy silane (APDMES, 97\%, Sigma) were used without any purification. Silanization of the nanopatterned PMMA was performed by placing the samples into a desiccator with $100 \mu \mathrm{l}$ of silane in a watch glass, pulling a vacuum, and leaving the desiccator overnight. The samples were then rinsed with $\mathrm{MeOH}$ and water, blown dry with Ar, and placed on a hot plate at $50^{\circ} \mathrm{C}$ for $3 \mathrm{~h}$.

\subsection{Gold nanoparticle synthesis}

$\mathrm{Au}$ NPs were synthesized as reported elsewhere [24]. A $100 \mathrm{ml}$ solution of $1 \mathrm{wt} \% \mathrm{HAuCl}_{4}: 3 \mathrm{H}_{2} \mathrm{O}$ (Sigma) in deionized water was brought to a boil under stirring and 1.00, 0.930, or $0.860 \mathrm{ml}$ of $10 \mathrm{wt} \%$ trisodium citrate (Sigma) in water was added to the solution to obtain 30, 37, and $50 \mathrm{~nm}$ diameter $\mathrm{Au}$ NPs, respectively. The solution turned bluish, then purplish, and eventually a bright red, indicating Au NP formation. The synthesis was allowed to run for $10 \mathrm{~min}$ before removing the solution from the heat and transferring it to $20 \mathrm{ml}$ vials. These vials were stored in a refrigerator until they were used.

\subsection{Nanopatterning}

The silanized nanopatterns were rinsed for $5 \mathrm{~s}$ with chloroform and dried under an Ar stream to remove the unexposed PMMA and to expose the $\mathrm{SiO}_{2}$ surface. The samples were then placed into a 'flat-mouth' alligator clip and fixed to the arm of a vertical dipper (Microslide stage with NSC-1S controller, Newmark Systems) using double-sided Scotch tape (3M). The sample was then lowered into $5 \mathrm{ml}$ of the Au NP solution. The solution was contained in the sawed-off bottom of a $20 \mathrm{ml}$ vial. In a typical experiment, the sample remained immersed in the Au NP solution for $20 \mathrm{~min}$ before being withdrawn from the solution at $10 \mu \mathrm{m} \mathrm{s}^{-1}$. The withdrawal rate was controlled by the dipper control software (Newmark Systems).

\subsection{Effects of the salt concentration on the nanopatterning}

Sodium chloride (Sigma) was used to create a $0.1 \mathrm{M}$ solution in deionized $\mathrm{H}_{2} \mathrm{O}$. To obtain the desired concentrations of $\mathrm{NaCl}$ in the $\mathrm{Au} \mathrm{NP}$ solution, $x \mathrm{ml}$ of $0.1 \mathrm{M} \mathrm{NaCl}$ solution was mixed with $5.0-x \mathrm{ml}$ of Au NP solution. For 1, 2, 5, and $10 \mathrm{mM} \mathrm{NaCl}$ concentrations, $x=0.05,0.10,0.25$, and $0.50 \mathrm{ml}$, respectively. Unless noted otherwise, the solutions 
were prepared by first adding $4 \mathrm{ml}$ of Au NP solution, then $x \mathrm{ml}$ of $\mathrm{NaCl}$ solution, and finally $1-x \mathrm{ml}$ of Au NP solution.

To test the effects when the $\mathrm{NaCl}$ is added to the $\mathrm{Au} \mathrm{NP}$ solution, a $1.0 \mathrm{M}$ solution of $\mathrm{NaCl}$ in deionized water was created. First a small volume $(100,150,200,300,500,900 \mu \mathrm{l})$ of the Au NP solution was added to a UV-vis cuvette. Then, $5 \mu \mathrm{l}$ of the $1 \mathrm{M} \mathrm{NaCl}$ solution was added to the cuvette. After shaking the cuvette to ensure good mixing, another small volume of $\mathrm{Au}$ NP solution was added to bring the total volume of the solution to $1 \mathrm{ml}$. The final $\mathrm{NaCl}$ concentration of all solutions was $5 \mathrm{mM}$. UV-vis was used to characterize the solutions after adding the $\mathrm{NaCl}$ and after adding the final volume of $\mathrm{Au} \mathrm{NP}$ solution.

\subsection{Characterization}

UV-visible spectra of the samples were recorded in a UV-vis Bio 50 (Cary). The size and distribution of the $\mathrm{Au}$ NPs were characterized by JEOL 3011 HRTEM transmission electron microscopy at $300 \mathrm{keV}$ (JEOL). TEM samples were prepared by drop casting $5 \mu \mathrm{l}$ of the Au NP solution onto a carbon-coated copper TEM grid (Ted Pella) and allowing the solution to evaporate. Assemblies of the nanopatterned $\mathrm{Au}$ NPs were imaged using scanning electron microscopy on a Nova Nanolab FIB/SEM (FEI) at $10 \mathrm{keV}$. Optical images were taken with an iPhone 4 (Apple).

\section{Results and discussion}

\subsection{Chemical template fabrication and nanopatterning}

The nanopatterning technique is illustrated in figure 1. EBL was performed on pieces of $\mathrm{Si}$ wafer that had been spin cast with a $65 \mathrm{~nm}$ thick PMMA resist to create arrays of dots. After developing the nanopatterns and a quick $\mathrm{O}_{2}$ plasma cleaning, the nanopatterns were given a positive charge by functionalizing the exposed $\mathrm{Si}$ with an aminosilane via gas-phase silanization in a desiccator under vacuum. Once functionalized, the sample was rinsed with chloroform to remove the unexposed PMMA resist, dried under Ar gas, and then dipped into an aqueous solution of citrate-capped $\mathrm{Au}$ NPs. The negatively charged, citrate-capped Au NPs self-assemble on the positively charged nanopatterns via a charge-charge interaction. The self-assembled Au NPs were then observed via scanning electron microscopy (SEM).

Dots were generated by focusing the electron beam on a specific point until the desired exposure dose was achieved. The size of the dots generated by EBL was controlled by varying the exposure dose of the electron beam in the PMMA resist. This technique can be used until the exposure dose is greater than $200 \mathrm{fC}$, at which point the electron beam begins to cross-link the PMMA resist. The cross-linked PMMA is not removed during development, and is therefore undesirable.

Initially, 3-aminopropyltrimethoxysilane (APTMS) was used to functionalize the nanopatterns. While APTMS was able to direct the self-assembly of the nanoparticles here and elsewhere [10], the functionalized areas would often feature a raised halo around which the nanoparticles would assemble, as seen in figure $\mathrm{S} 1$ (a) (supporting information available at stacks.iop.org/Nano/23/045602/mmedia). This halo was most likely due to the gelation of the APTMS during the gas-phase silanization [25]. In order to prevent the formation of this halo, 3-aminopropyldimethylethoxysilane (APDMES) was used to functionalize the nanopatterns. APDMES features only one ethoxy-group, which has much lower reactivity and therefore deters the self-gelation during gas-phase silanization, but still enables monolayer formation and nanoparticle assembly, as seen in figure S1(b) (supporting information available at stacks.iop.org/Nano/23/045602/mmedia).

Unlike other attempts to electrostatically pattern negatively charged Au NPs using aminosilanes, neither resist nor an additional functional molecule was used to inhibit non-specific adhesion of the Au NPs to the substrate. The bare $\mathrm{SiO}_{2}$ surface proved more than capable of preventing non-specific adhesion of the Au NPs.

\subsection{Controlling the number of nanoparticles that self-assemble}

Monomers, dimers, trimers, and quatramers citrate-capped $\mathrm{Au}$ NPs of $37 \mathrm{~nm}$ diameter were formed on 41, 50, 56, and $69 \mathrm{~nm}$ diameter aminosilane nanodots, as seen in figures 2(a)-(d). The number of particles that assemble on the positively charged nanodot should increase as the size of the nanodot increases. It was previously reported that colloids would assemble until the electric field of the negatively charged colloids compensated for the electric field of the positively charged chemical template $[9,11]$. Therefore, if the size of the nanoparticles is altered, then it should be expected that different numbers of nanoparticles will assemble on the same sized nanodot.

Citrate-capped Au NPs were synthesized [24] with 29.6土 $4.5,36.5 \pm 5.1$, and $50.3 \pm 10.3 \mathrm{~nm}$ diameters, as confirmed by transmission electron microscopy. Figure 3 shows the number of Au NPs that assembled on different sized nanodots for the 30, 37, and $50 \mathrm{~nm}$ diameter Au NPs. As expected, as the size of the nanoparticle increased, the number of nanoparticles that deposited decreased for the same sized pattern. This is a result of the increased negative electric field of the larger nanoparticles due to the increased size and surface area of larger nanoparticles. Thus, fewer nanoparticles were necessary to compensate for the electric field of the positively charged aminosilane nanodot. The variance in the number of nanoparticles that assemble on the nanodot was always less than one and was due to the variance in the size of both the nanoparticles and the nanodots. If it were possible to manufacture monodisperse nanoparticles and nanodots, it would be expected that the number of nanoparticles that assemble on a nanodot would be more uniform. Furthermore, the choice of nanoparticle size was limited by the EBL system, which has a theoretical $20 \mathrm{~nm}$ feature resolution.

While the number of particles that self-assemble could be controlled by manipulating the sizes of the Au NPs and the nanodots, the spatial registry could not be controlled. A previous study showed that there was significant variance of the location of a single, electrostatically patterned $\mathrm{Au}$ NP within the nanodots [22]. The lack of controlled spatial registry is a limitation of electrostatic patterning. 
(a)

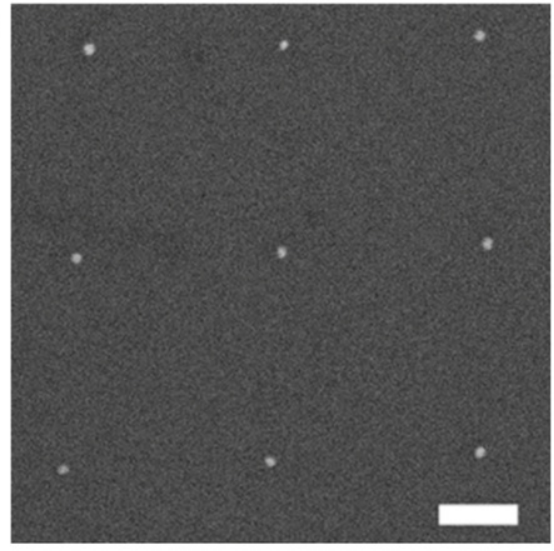

(c)

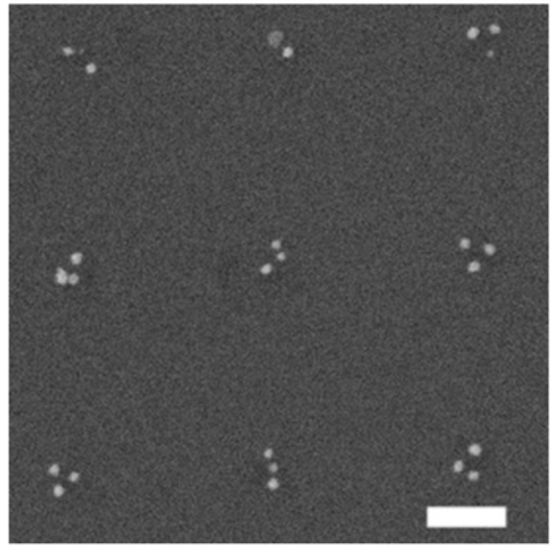

(b)

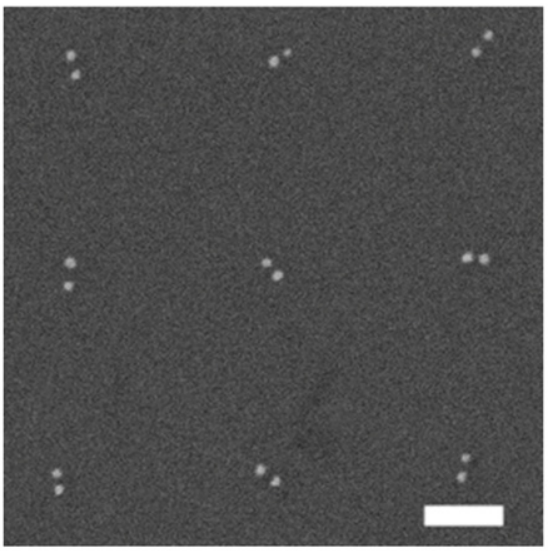

(d)

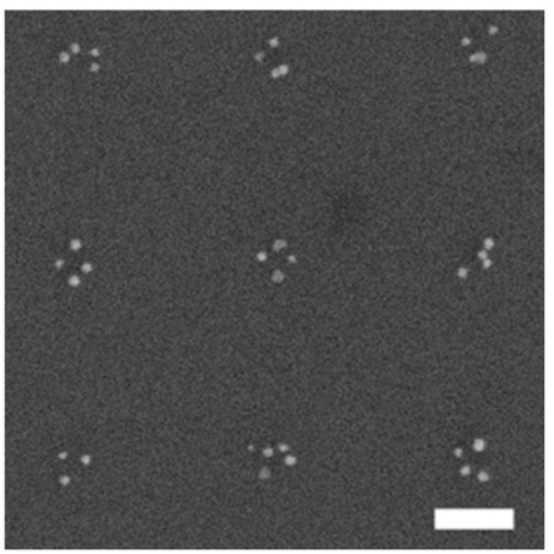

Figure 2. Au NPs assembled as (a) monomers, (b) dimers, (c) trimers, and (d) quatramers on 41, 50, 56, and 69 nm diameter nanodots, respectively. The scale bars are $200 \mathrm{~nm}$.

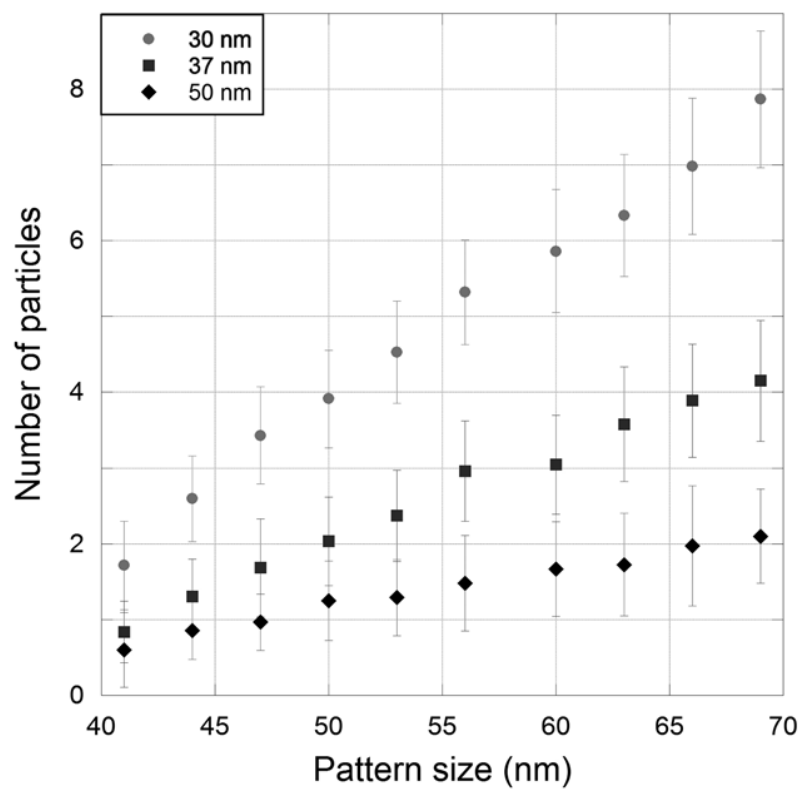

Figure 3. Plot of the number of particles that assemble on nanodots for different sized nanoparticles.

\subsection{Effect of the immersion time on the nanopatterning}

In previous work on the electrostatic assembly of nanoparticles, substrates were left in the nanoparticle solutions overnight to reach equilibrium [9]. However, the electrostatic assembly should be rather fast due to the strong attraction between the negatively charged particles and the positively charged nanopattern. In order to determine exactly how long this system takes to reach equilibrium, samples were immersed in $50 \mathrm{~nm}$ Au NP solutions for 10, 20, 30, and 60 min. The number of Au NPs that assemble on different sizes of aminosilane nanodots for the aforementioned immersion times is summarized in figure 4. The standard deviations are omitted for clarity, but it should be noted that the standard deviations were no more than 0.73 for all data points. Thus, it can be concluded that there is no difference in the number of particles that assemble depending on whether the immersion time is greater than $10 \mathrm{~min}$.

From the data, it appears that longer immersion times are of little consequence. The diffusion constant, $D$, of a Au NP in solution can be calculated using the Stokes-Einstein equation:

$$
D=\frac{k_{\mathrm{b}} T}{6 \pi \eta r}
$$

where $k_{\mathrm{b}}$ is the Boltzmann constant, $T$ is the temperature of the solution $(300 \mathrm{~K}), \eta$ is the viscosity of the solution (1 $\mathrm{cP}$ ), and $r$ is the radius of the particle. For a $50 \mathrm{~nm} \mathrm{Au} \mathrm{NP}$, $D \sim 878.9 \mathrm{~nm}^{2} \mathrm{~s}^{-1}$, and the diffusion length, $(D t)^{3 / 2}$, of the particle is $\sim 34.2 \mu \mathrm{m}^{3}$ after $20 \mathrm{~min}$. For a $1 \mathrm{wt} \%$ solution of $50 \mathrm{~nm} \mathrm{Au} \mathrm{NPs,} \mathrm{there} \mathrm{is} \mathrm{approximately} \mathrm{one} \mathrm{nanoparticle} \mathrm{per}$ $12.6 \mu \mathrm{m}^{3}$. Since the particle can diffuse outside of its 'box' in 


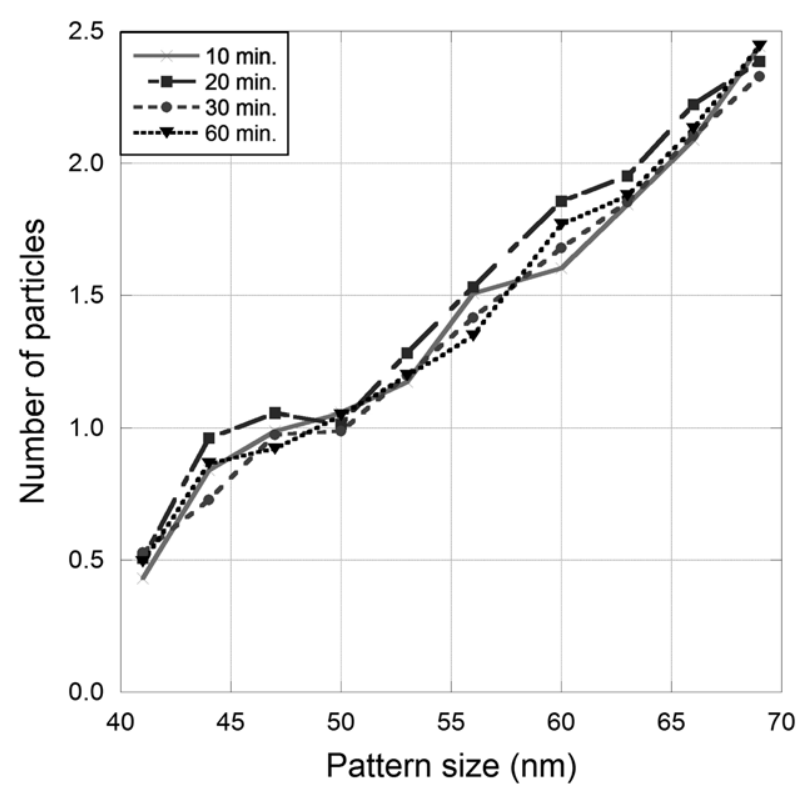

Figure 4. Plot of the number of particles that assemble on different sized nanodots for different immersion times in the Au NP solution. Despite the different immersion times in the nanoparticle solution, the number of particles that assemble does not vary.

20 min simply through Brownian motion, it is safe to say that after $20 \mathrm{~min}$, under the influence of an attractive electrostatic force, the negatively charged Au NPs should self-assemble in an equilibrium manner.

\subsection{Effect of the salt concentration on the nanopatterning}

The effect of the salt concentration on the loading density of the Au NPs was also investigated. It was expected that by introducing $\mathrm{NaCl}$, the salt would screen the repulsion between the like-charged Au NPs and a larger number of particles would self-assemble on the same sized nanodot. Samples were dipped for $20 \mathrm{~min}$ in $30 \mathrm{~nm} \mathrm{Au} \mathrm{NP}$ solutions with $\mathrm{NaCl}$ concentrations of $0,1,2,5$, and $10 \mathrm{mM}$, and withdrawn at $10 \mu \mathrm{m} \mathrm{s}^{-1}$. The numbers of particles that assembled on various sized nanodots are summarized in figure 5. As the $\mathrm{NaCl}$ concentration increased, the number of particles that deposited on the nanopattern increased, as expected due to the charge screening effects of the $\mathrm{NaCl}$. Curiously, the $\mathrm{NaCl}$ does not seem to have as great an effect at screening the positive charge from the aminosilane nanodot, since the self-assembly is still very fast. Since the number of nanoparticles that self-assembled increased as the salt concentration increased, the standard deviations for those data points were greater than those from lower salt concentrations.

Since the Au NPs are better screened from one another's charge-charge repulsion, the Au NPs are able to more closely pack on each nanodot. Further evidence of the screening effects of the $\mathrm{NaCl}$ is seen in the SEM images of samples from the $\mathrm{NaCl}$ study, figure 6 . In figure 6 there is some non-specific deposition as a result of the charge screening effects of $\mathrm{NaCl}$. What is interesting is that when $\mathrm{NaCl}$ is added to the $\mathrm{Au} \mathrm{NP}$ solution too soon, the concentration spike of $\mathrm{NaCl}$ causes the

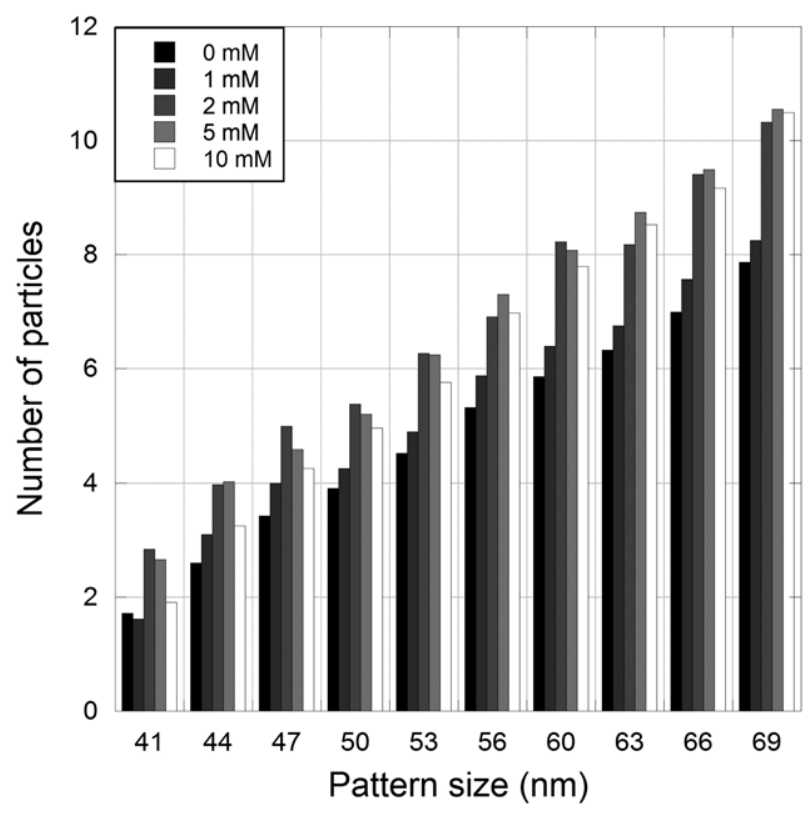

Figure 5. Plot of the number of particles that assemble on different sized nanodots for different concentrations of $\mathrm{NaCl}$.

Au NP solution to turn from red to purple until additional $\mathrm{Au}$ NP solution is added. The change in color suggests that the $\mathrm{NaCl}$ is effective enough at screening the particle-particle repulsion to enable aggregation of the Au NPs. This is evident in figure 6(b), which shows enhanced non-specific deposition. Conversely, when the $\mathrm{NaCl}$ was added when the Au NP solution was nearly at total volume, there was no color change in the solution and very little non-specific deposition. Thus, the order in which the $\mathrm{NaCl}$ is added is crucial to the patterning of the Au NPs.

\subsection{Aggregation of nanoparticles as a result of spikes in the salt concentration}

The importance of when the $\mathrm{NaCl}$ is added to the Au NP solution was further investigated. A small volume of Au NP solution was added to a UV-vis cuvette, then $5 \mu \mathrm{l}$ of $1 \mathrm{M}$ $\mathrm{NaCl}$ was added to the cuvette, and finally additional $\mathrm{Au}$ NP solution was added to bring the total solution volume to $1 \mathrm{ml}$. The final $\mathrm{NaCl}$ concentration was always $5 \mathrm{mM}$. Table 1 shows the different volumes of Au NP solution that were added and the intermediate $\mathrm{NaCl}$ concentration after the $\mathrm{NaCl}$ was added to the first volume of Au NP solution. In the case of the $100 \mu \mathrm{l} \mathrm{Au} \mathrm{NP}$ solution, the $\mathrm{NaCl}$ concentration reached $43.5 \mathrm{mM}$. The solution color changed from red to purple to clear after adding the $\mathrm{NaCl}$, indicating $\mathrm{Au} \mathrm{NP}$ aggregation. This was the only solution that showed any noticeable color change after the addition of $\mathrm{NaCl}$. UV-vis was used to further probe for any Au NP aggregation. UV-vis spectra for all solutions after adding $\mathrm{NaCl}$ and in their final state are shown in figure S2 (supporting information available at stacks.iop. org/Nano/23/045602/mmedia). From the UV-vis spectra, it would appear that there is some aggregation in the other solutions. The amount of aggregation decreases the later the $\mathrm{NaCl}$ is added to the solution. All of the final solutions 
(a)

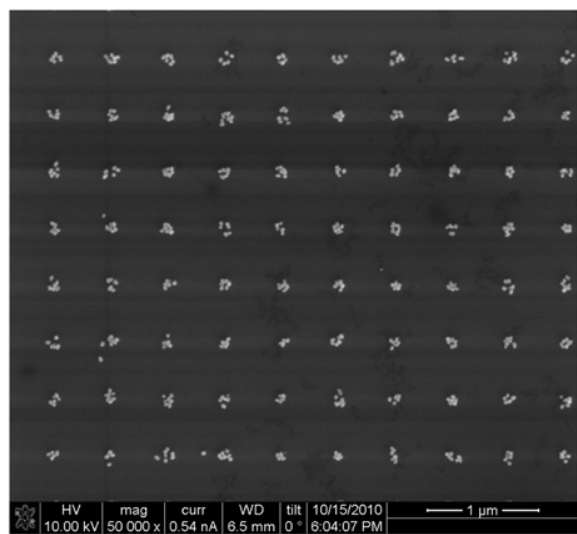

(b)

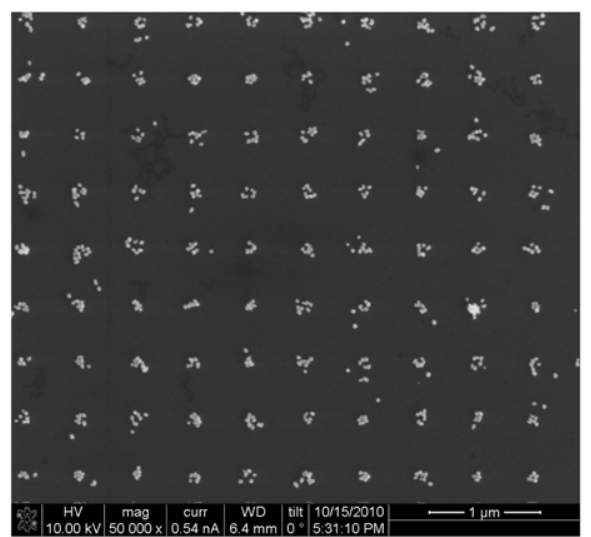

Figure 6. Citrate-capped, $37 \mathrm{~nm}$ Au NPs patterned on $69 \mathrm{~nm}$ aminosilane nanodots from a $1 \mathrm{mM} \mathrm{NaCl}$ solution of Au NPs. For (a), the solution was prepared by adding $4 \mathrm{ml}$ of Au NP solution, $50 \mu \mathrm{l}$ of $0.1 \mathrm{M} \mathrm{NaCl}$, and then $0.95 \mathrm{ml}$ of additional Au NP solution. For (b) the solution was prepared by adding $1 \mathrm{ml}$ of Au NP solution, $50 \mu \mathrm{l}$ of $0.1 \mathrm{M} \mathrm{NaCl}$, and then $3.95 \mathrm{ml}$ of additional Au NP solution. Adding the $\mathrm{NaCl}$ to the solution too soon can result in additional non-specific deposition as seen in (b).

Table 1. A list of the solutions for the study of the effect of when the $\mathrm{NaCl}$ is added on the aggregation of the Au NPs. The intermediate $\mathrm{NaCl}$ concentration is also listed for each solution. The final $\mathrm{NaCl}$ concentration for each solution was $5 \mathrm{mM}$.

\begin{tabular}{llll}
\hline $\begin{array}{l}\text { Initial } \mathrm{Au} \\
\mathrm{NP} \text { volume } \\
(\mu \mathrm{l})\end{array}$ & $\begin{array}{l}\text { Volume of } \\
1 \mathrm{M} \mathrm{NaCl} \\
(\mu \mathrm{l})\end{array}$ & $\begin{array}{l}\text { Final } \mathrm{Au} \\
\text { NP volume } \\
(\mu \mathrm{l})\end{array}$ & $\begin{array}{l}\text { Intermediate } \mathrm{NaCl} \\
\text { concentration }(\mathrm{mM})\end{array}$ \\
\hline 100 & 5 & 895 & 47.6 \\
150 & 5 & 845 & 32.3 \\
200 & 5 & 795 & 24.4 \\
300 & 5 & 695 & 16.4 \\
500 & 5 & 495 & 9.9 \\
995 & 5 & 0 & 5.0 \\
\hline
\end{tabular}

appeared red in color, but the second absorption peak around $800 \mathrm{~nm}$ was greatest for the solutions in which the $\mathrm{NaCl}$ was added sooner. Thus, even though the solutions are still red, there is still some irreversible aggregation that occurs when the $\mathrm{NaCl}$ is added due to the charge screening.

The Debye length, $\kappa^{-1}$, is the scale over which mobile charge carriers screen out electric fields. The Debye length provided by an ionic salt is given by

$$
\kappa^{-1}=\left(8 \pi N_{\mathrm{A}} \lambda_{\mathrm{B}} I\right)^{-1 / 2}
$$

where $\lambda_{\mathrm{B}}$ is the Bjerrum length of the medium $(\sim 0.7 \mathrm{~nm}$ for water at room temperature), $N_{\mathrm{A}}$ is Avogadro's number, and $I$ is the concentration of the salt in $\mathrm{mol} \mathrm{dm}^{-3}\left(\mathrm{~mol} \mathrm{l}^{-1}\right)$. As the concentration of the $\mathrm{NaCl}$ increases, the screening length exponentially decreases. At $50 \mathrm{mM}, \kappa^{-1}=1.37 \mathrm{~nm}$, so the Au NPs can get fairly close to each other. Based on the intermediate concentrations listed in table 1, it appears that $\mathrm{Au}$ NP aggregation aggressively begins when the Debye length reaches a critical value between 1.71 and $1.41 \mathrm{~nm}$. In other words, once the Au NPs are able to get within $\sim 1.5 \mathrm{~nm}$ of each other, the Au NPs are able to aggregate.

Previous work on the electrostatic self-assembly of $\mathrm{Au}$ NPs on aminosilane chemical functionalized nanopatterned surfaces suggested that there was a permanent bond between the Au NP and the aminosilane [9]. However, the conditions present are not suitable to form an amide bond [26, 27]. Therefore, the only forces that may be present to bind the $\mathrm{Au}$ NP to the substrate would be van der Waals forces and the electrostatic forces. In order to investigate the relative strength of these forces, an aminosilane functionalized nanopatterned surface with already patterned Au NPs was immersed in a $10 \mathrm{mM} \mathrm{NaOH}$ solution for $10 \mathrm{~h}$. SEM images of the patterned $\mathrm{Au}$ NPs before and after immersion in the $\mathrm{NaOH}$ are seen in figure 7. It was expected that in the $\mathrm{NaOH}$ solution the APDMES would be deprotonated, since the $\mathrm{pK}_{\mathrm{a}}$ of the tertiary amine is $\sim 9.5$ and a $10 \mathrm{mM}$ solution of $\mathrm{NaOH}$ has a calculated $\mathrm{pH}$ of 12. It was found that at a $\mathrm{pH}$ of 11, no $\mathrm{Au}$ NPs would self-assemble on the APDMES patterned substrate (figure S3, supporting information available at stacks.iop. org/Nano/23/045602/mmedia). However, no Au NPs were displaced or rearranged after the immersion in $\mathrm{NaOH}$. Only after sonicating the sample in $10 \mathrm{mM} \mathrm{NaOH}$ for $15 \mathrm{~min}$ do the $\mathrm{Au}$ NPs begin to be disturbed. As seen in the sonicated SEM images in figure 7, some Au NPs have been liberated. After 60 min of sonication, no Au NPs remained on the nanopatterned surface. Furthermore, when using higher concentrations of $\mathrm{NaOH}$, sonication was still necessary to remove the Au NPs. This suggests that the van der Waals forces are holding the Au NPs on the template even in the absence of the electrostatic force. This confirms a previous result which showed that the van der Waals forces dominate as a citrate-capped Au NP moves within $10 \mathrm{~nm}$ of an aminosilane patterned $\mathrm{SiO}_{2}$ surface [17]. When the distance between the $\mathrm{Au} \mathrm{NP}$ and the surface was $1 \mathrm{~nm}$, the binding energy due to van der Waals forces was calculated to be $1.19 \mathrm{eV}$. At $300 \mathrm{~K}$, the thermal kinetic energy $\left(1.5 k_{\mathrm{b}} T\right)$ of the Au NP is calculated to be $38.7 \mathrm{meV}$. Thus, the additional sonication was necessary to overcome the van der Waals forces to liberate the Au NPs bound to the substrate.

\section{Conclusion}

In conclusion, a straightforward and effective technique to pattern Au NPs using chemically modified nanopatterned 

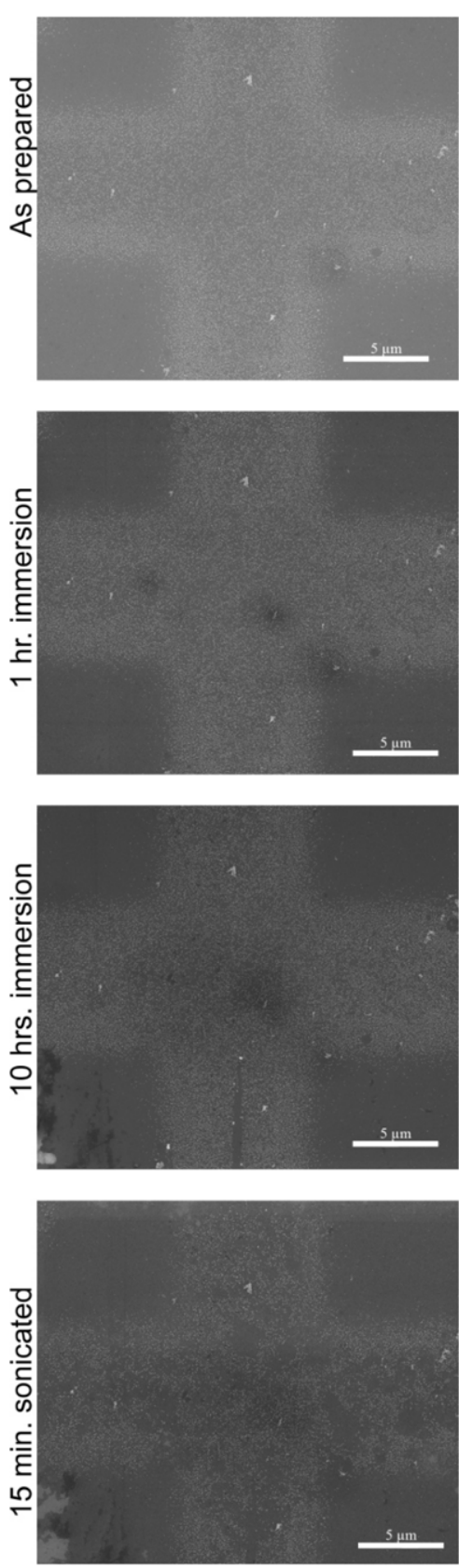

Figure 7. SEM images of a sample of self-assembled Au NPs on a large alignment mark that were exposed to a $10 \mathrm{mM} \mathrm{NaOH}$ solution for various times and conditions in order to lift off the Au NPs.

surfaces was demonstrated. Unlike other systems that use aminosilanes to electrostatically pattern Au NPs, this system does not require an additional functional molecule to prevent non-specific deposition on unpatterned areas. The system allows very fast assembly of the Au NPs, taking only 20 min to reach equilibrium. Using $\mathrm{NaCl}$ to screen the inter-particle repulsion allowed for greater numbers of particles to assemble on the same sized chemical nanopattern. However, great care should be taken when preparing the Au NP solution with $\mathrm{NaCl}$ to prevent unwanted Au NP aggregation. Furthermore, in addition to neutralizing the electrostatic attraction, agitation such as sonication is necessary to remove the self-assembled $\mathrm{Au}$ NPs from the chemically modified nanopatterned surface due to the strong van der Waals forces between the Au NPs and the $\mathrm{SiO}_{2}$ substrate. This technique could be extended to any charged nanoparticle and should allow for precise patterning of nanoparticles for use in sensors, photonic crystals, and other devices.

\section{Acknowledgments}

This work was supported by the Air Force Office of Scientific Research (AFOSR) under contract FA 9550-06-01-0279 through the Multidisciplinary University Research Initiative Program. Portions of this work were performed at the Lurie Nanofabrication Facility at the University of Michigan and at the Electron Microbeam Analysis Laboratory at the University of Michigan.

\section{References}

[1] Maury P A, Reinhoudt D N and Huskens J 2008 Assembly of nanoparticles on patterned surfaces by noncovalent interactions Curr. Opin. Colloid Interface Sci. 13 74-80

[2] Zhang J, Li Y, Zhang X and Yang B 2010 Colloidal self-assembly meets nanofabrication: from two-dimensional colloidal crystals to nanostructure arrays $A d v$. Mater. 22 4249-69

[3] Crespo-Biel O, Ravoo B J, Reinhoudt D N and Huskens J 2006 Noncovalent nanoarchitectures on surfaces: from 2D to 3D nanostructures J. Mater. Chem. 16 3997-4021

[4] Kinge S, Crego-Calama M and Reinhoudt D N 2008 Self-assembling nanoparticles at surfaces and interfaces ChemPhysChem 9 20-42

[5] Min Y, Akbulut M, Kristiansen K, Golan Y and Israelachvili J 2008 The role of interparticle and external forces in nanoparticle assembly Nature Mater. 7 527-38

[6] Shenhar R, Norsten T B and Rotello V M 2005 Polymer-mediated nanoparticle assembly: structural control and applications Adv. Mater. 17 657-69

[7] Zhang J, Sun Z and Yang B 2009 Self-assembly of photonic crystals from polymer colloids Curr. Opin. Colloid Interface Sci. 14 103-14

[8] Covington E, Bohrer F I, Xu C, Zellers E T and Kurdak C 2010 Densely integrated array of chemiresistor vapor sensors with electron-beam patterned monolayerprotected gold nanoparticle interface films Lab Chip $103058-60$

[9] Manandhar P, Akhadov E A, Tracy C and Picraux S T 2010 Integration of nanowire devices in out-of-plane geometry Nano Lett. 10 2126-32

[10] Maury P, Escalante M, Reinhoudt D N and Huskens J 2005 Directed assembly of nanoparticles onto polymer-imprinted or chemically patterned templates fabricated by nanoimprint lithography Adv. Mater. 172718

[11] Lee I, Zheng H P, Rubner M F and Hammond P T 2002 Controlled cluster size in patterned particle arrays via directed adsorption on confined surfaces Adv. Mater. 14 572-7

[12] Lee H, You S, Pikhitsa P V, Kim J, Kwon S, Woo C G and Choi M 2010 Three-dimensional assembly of nanoparticles from charged aerosols Nano Lett. 11 119-24

[13] Zheng H P, Lee I, Rubner M F and Hammond P T 2002 Two component particle arrays on patterned polyelectrolyte multilayer templates Adv. Mater. 14 569-72

[14] Ling X Y, Malaquin L, Reinhoudt D N, Wolf H and Huskens J 2007 An in situ study of the adsorption behavior of functionalized particles on self-assembled monolayers via different chemical interactions Langmuir 23 9990-9 
[15] Ofir Y, Samanta B, Xiao Q, Jordan B J, Xu H, Arumugam P, Arvizo R, Tuominen M T and Rotello V M 2008 Polyelectrolyte negative resist patterns as templates for the electrostatic assembly of nanoparticles and electroless deposition of metallic films Adv. Mater. 20 2561-6

[16] Chen K M, Jiang X, Kimerling L C and Hammond P T 2000 Selective self-organization of colloids on patterned polyelectrolyte templates Langmuir 16 7825-34

[17] Ma L-C, Subramanian R, Huang H-W, Ray V, Kim C-U and Koh S J 2007 Electrostatic funneling for precise nanoparticle placement: a route to wafer-scale integration Nano Lett. 7 439-45

[18] Ling X, Zhu X, Zhang J, Zhu T, Liu M, Tong L and Liu Z 2005 Reproducible patterning of single Au nanoparticles on silicon substrates by scanning probe oxidation and self-assembly J. Phys. Chem. B 109 2657-65

[19] Li Q G, Zheng J W and Liu Z F 2003 Site-selective assemblies of gold nanoparticles on an AFM tip-defined silicon template Langmuir 19 166-71

[20] Zheng J W, Zhu Z H, Chen H F and Liu Z F 2000 Nanopatterned assembling of colloidal gold nanoparticles on silicon Langmuir 16 4409-12
[21] Xu H, Hong R, Wang X Y, Arvizo R, You C C, Samanta B, Patra D, Tuominen M T and Rotello V M 2007 Controlled formation of patterned gold films via site-selective deposition of nanoparticles onto polymer-templated surfaces Adv. Mater. 191383

[22] Huang H W, Bhadrachalam P, Ray V and Koh S J 2008 Single-particle placement via self-limiting electrostatic gating Appl. Phys. Lett. 93073110

[23] Zhu T, Zhang X, Wang J, Fu X Y and Liu Z F 1998 Assembling colloidal Au nanoparticles with functionalized self-assembled monolayers Thin Solid Films 327 595-8

[24] Frens G 1973 Controlled nucleation for regulation of particle-size in monodisperse gold suspensions Nature Phys. Sci. 241 20-2

[25] Pallandre A, Glinel K, Jonas A M and Nysten B 2004 Binary nanopatterned surfaces prepared from silane monolayers Nano Lett. 4 365-71

[26] Carey F A 2003 Organic Chemistry (New York: McGraw-Hill)

[27] Gunanathan C, Ben-David Y and Milstein D 2007 Direct synthesis of amides from alcohols and amines with liberation of $\mathrm{H}_{2}$ Science 317 790-2 